\title{
Effect of Solution Heat Treatment Time on a \\ Rheocast Al-Zn-Mg-Cu Alloy
}

\author{
Nonjabuliso E. Mazibuko ${ }^{1, a}$ and Ulyate A. Curle 2 , b \\ ${ }^{1}$ Materials Science and Manufacturing, Council for Scientific and Industrial Research (CSIR), \\ Pretoria, South Africa \\ aNMazibuko@csir.co.za, ${ }^{\mathrm{b} U C u r l e @ c s i r . c o . z a ~}$
}

Keywords: CSIR-RCS; eutectic phase; intermetallic phases; hardness

\begin{abstract}
During rheo-high pressure die casting (R-HPDC) of Al-Zn-Mg-Cu alloys a coarse eutectic phase is formed. This eutectic phase is difficult to take into solution because of its size and it would require longer solution heat treatment times. The objective of this work was to determine the time for sufficient dissolution of the eutectic phase in this Al- $\mathrm{Zn}-\mathrm{Mg}-\mathrm{Cu}$ alloy. Solution heat treatment was carried out at $473^{\circ} \mathrm{C}$ for various time periods and the samples were quenched in water. The samples were then artificially aged at $120^{\circ} \mathrm{C}$ for 24 hrs. A component of the eutectic was observed to have dissolved and another component transformed to new intermetallic phases for all solution heat treatment times at $473^{\circ} \mathrm{C}$.
\end{abstract}

\section{Introduction}

During rheo-high pressure die casting (R-HPDC) of Al-Zn-Mg-Cu alloys a coarse eutectic phase is formed [1]. This is a result of the solute redistribution during solidification which leads to microsegregation of elements. The eutectic phase is difficult to take into solution because of its size and it would require longer solution heat treatment times. The coarse eutectic phase has a significant effect on the properties of the 7xxx aluminium alloys [l-4]. When Al-Zn-Mg-Cu alloys are solution treated the eutectic dissolves and new intermetallic phases are formed which require higher solution treatment temperatures and longer times to dissolve [2, 5]. It was also observed that the mechanical properties increased considerably with no loss of ductility after stepped heat treatment [5]. The corrosion resistance was observed to improve after solution treatment of the similar AA7150 alloy [6]. The aim of this work was to determine a sufficient time for complete dissolution of the eutectic phase in this rheocast Al-Zn-Mg-Cu alloy.

\section{Experimental Procedure}

The Al-Zn-Mg-Cu alloy with the composition (6.7 Zn, $2.6 \mathrm{Mg}, 2.0 \mathrm{Cu}, 0.06 \mathrm{Fe}$, Si not detected and balance $\mathrm{Al}$, in wt.\%) was used for rheo-high pressure casting of the plate samples with dimensions $100 \mathrm{~mm} \times 55 \mathrm{~mm} \times 6 \mathrm{~mm}$. The alloy material was melted in a $20 \mathrm{~kg}$ resistance heated tilting furnace and degassed with argon. A sample was analyzed for chemical composition by optical emission spectroscopy (Thermo Quantris OES). Thermodynamic properties of the alloy were calculated with an aluminum thermodynamic database (ProCast 2009.1) from the specific OES composition. A pouring temperature of $650{ }^{\circ} \mathrm{C}$ and a SSM processing temperature of $615^{\circ} \mathrm{C}$ which corresponded to a solid fraction of $30 \%$ were used from experience with the system. The sequence for casting was as follows. Liquid metal was poured from the tilting furnace into the stainless steel processing cup (about 400 g) which was then manually transferred to a single coil version of the CSIR-RCS (induction stirring with simultaneous forced air cooling) where processing starts when the cup enters the coil. The thermocouple was used to measure the semi-solid temperature of the material in the cup. Processing stopped after the thermocouple signal reached the preset SSM temperature of $615{ }^{\circ} \mathrm{C}$. The cup was then ejected from the coil and manually transferred to the 
HPDC machine (LK DCC130). The injection shot was manually triggered when the SSM billet was in the shot sleeve. The piston followed the set computer controlled injection velocity profile.

The plate sample was then sectioned and solution heat treatment was performed at different time intervals to assess the effect of time on the dissolution of the eutectic phase. The solution heat treatment was carried out at $473^{\circ} \mathrm{C}$ for 15 minutes intervals up to $5 \mathrm{hrs}$ and at $4 \mathrm{hr}$ intervals up to 24 hrs, followed by quenching in water $\left(25^{\circ} \mathrm{C}\right)$, giving the $\mathrm{T} 4$ temper condition. Artificial ageing was performed at $120^{\circ} \mathrm{C}$ for 24 hrs for all the T4 samples. Vickers hardness was measured on the samples cross-sections after T4 and T6 samples using a $10 \mathrm{kgf}$ load and the average of nine readings is presented. Metallographic samples were prepared for optical microscope evaluation. A Joel JSM-6510 Scanning Electron Microscopy (SEM) equipped with the Thermo Scientific UltraDry X-ray Energy Dispersive Spectroscopy (EDS) was used to analyse the phases before and after solution heat treatment. The samples were evaluated in the unetched condition.

\section{Results and Discussion}

The hardness after solution treating at $473^{\circ} \mathrm{C}$ and quenching in water $\left(25^{\circ} \mathrm{C}\right)$ at different time intervals seemed relatively insensitive to the solution treatment time (Fig. 1). The error bars show maximum and minimum values for the plotted average values. The hardness peak observed after near 5hrs of solution treatment could be a result of the indentation falling on more patches of the eutectic. Overall, longer solution heat treatment times do not seem to be significant. Fig. 2 shows the as-cast microstructure consisting of globular alpha grains and the coarse eutectic phase, shrinkage porosity was also observed in the eutectic areas. The pores coalesced and became large with longer solution heat treatment time. Fig. 3(a) and 3(b) show the appearance of the eutectic areas after 5hrs and 24 hrs. Intermetallic phases were observed to have formed in the eutectic and these intermetallic phases coarsened with longer solution treatment time. The phases were analysed by EDS and they were found to have compositions as outlined in Table 1. The two phases in the solution treated samples have stochiometric compositions close to the AlCuMgZn for Phase 1 and $\mathrm{Al}_{2} \mathrm{CuMg}$ for Phase 2. The $\mathrm{Al}_{2} \mathrm{CuMg}$ phase has been observed to appear after 30 min of homogenization at $460^{\circ} \mathrm{C}$ for another $\mathrm{Al}-\mathrm{Zn}-\mathrm{Mg}-\mathrm{Cu}$ alloy [3] which seems to be the case for this study. The $\mathrm{Al}_{2} \mathrm{CuMg}$ phase was observed to have grown and coarsened into isolated patches Fig. (3b) after $24 \mathrm{hrs}$ of solution heat treatment. Solution heat treatment for $24 \mathrm{hrs}$ at $473^{\circ} \mathrm{C}$ was sufficient to dissolve the eutectic for this alloy but higher temperatures are required to completely dissolve the product intermetallic phases.

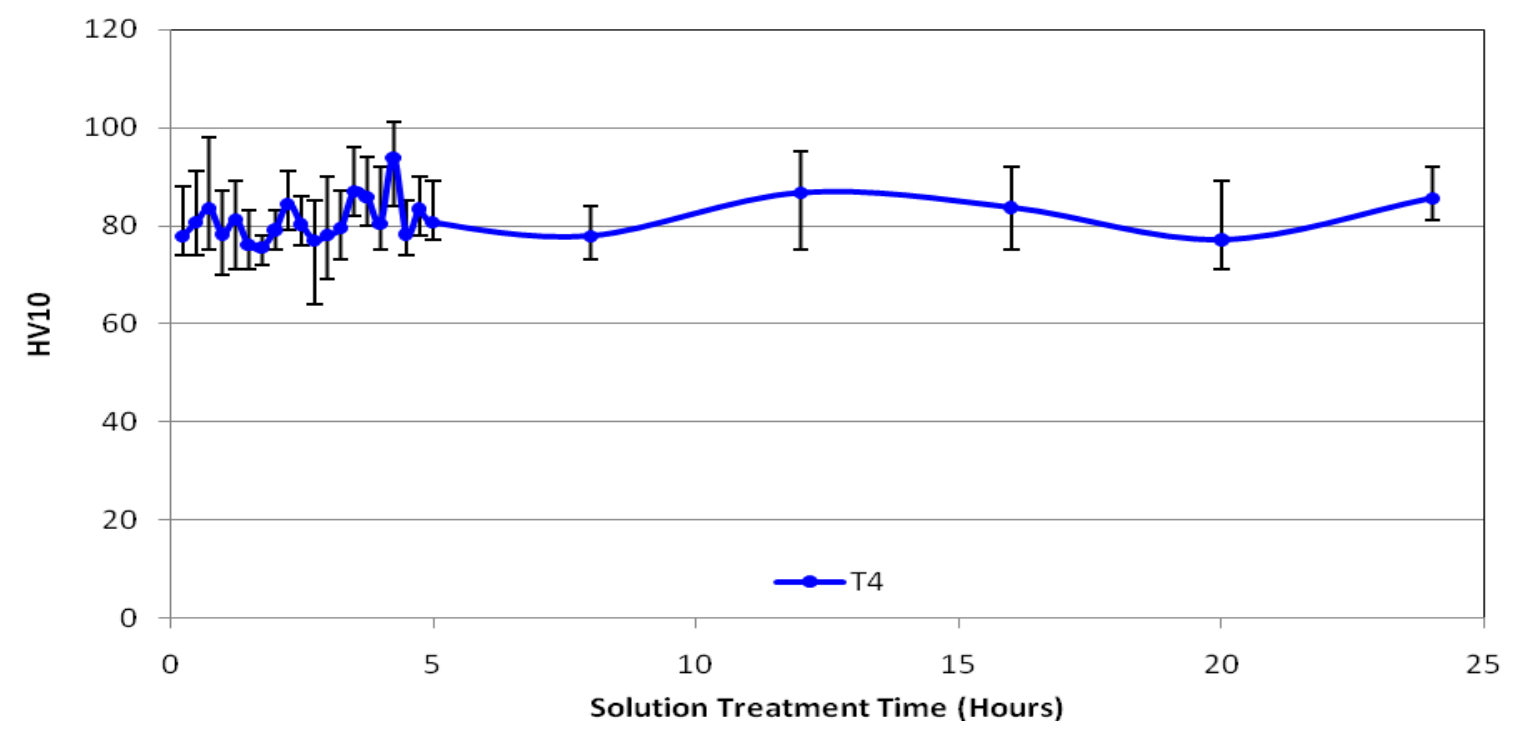

Fig. 1. Vickers Hardness Curve for the rheocast Al-Zn-Mg-Cu alloy after solution heat treatment at $473^{\circ} \mathrm{C}$ and water quench $\left(25^{\circ} \mathrm{C}\right)$. 


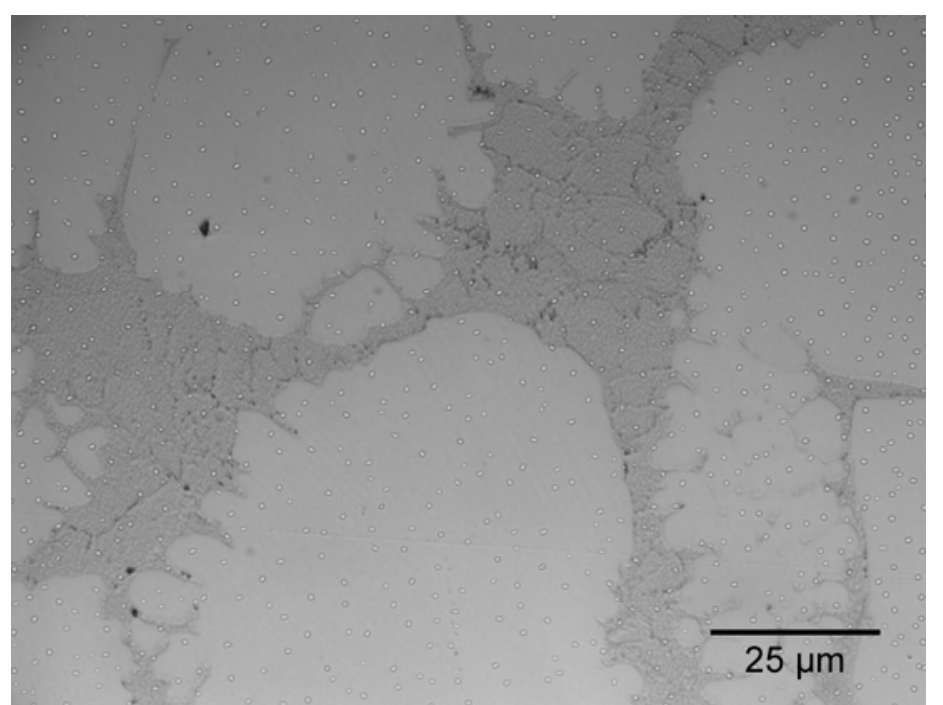

Fig. 2. Optical micrograph of the as-cast Al-Zn-Mg-Cu alloy.
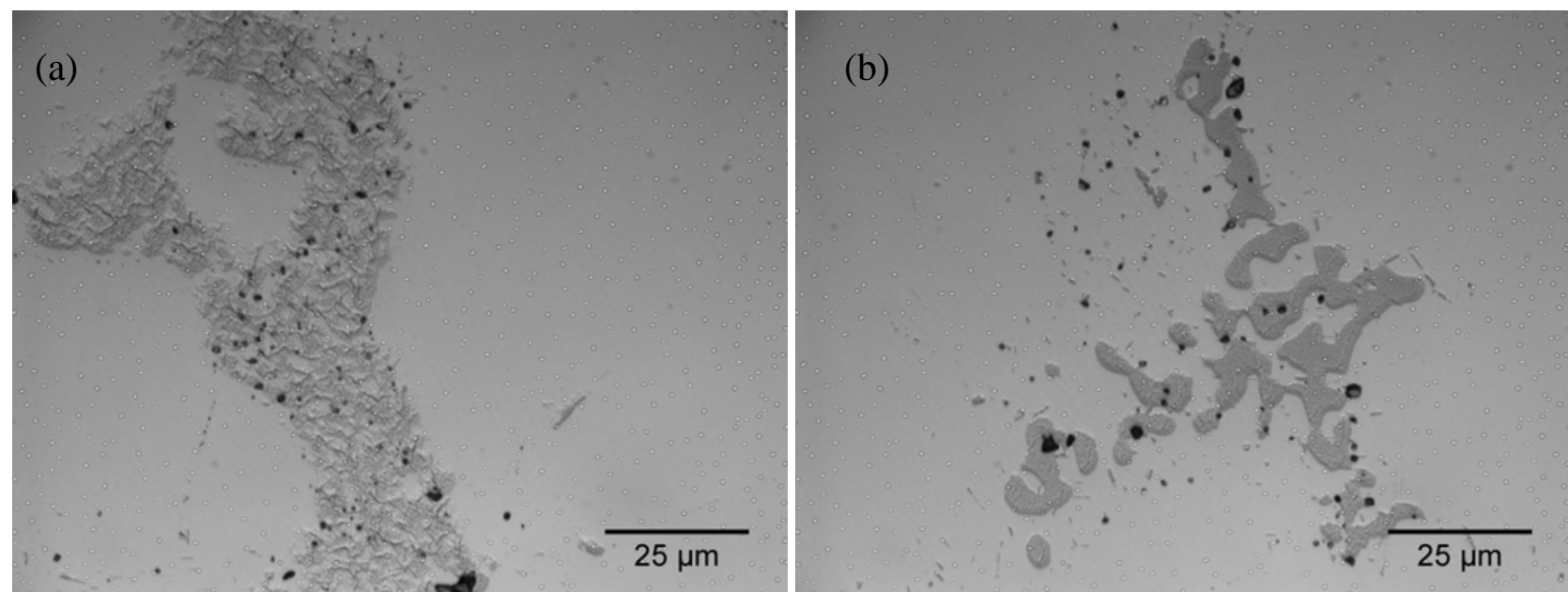

Fig. 3. Optical micrographs of (a) Al-Zn-Mg-Cu alloy after solution heat treatment at $473^{\circ} \mathrm{C}$ for 5 hrs and (b) after solution heat treatment at $473^{\circ} \mathrm{C}$ for $24 \mathrm{hrs}$.

Table 1: Results of EDS analysis of various types of the Phases shown in Fig. 2. (at. \%)

\begin{tabular}{|l|c|c|c|c|}
\hline Second Phase structure & $\mathrm{Al}$ & $\mathrm{Zn}$ & $\mathrm{Mg}$ & $\mathrm{Cu}$ \\
\hline As-cast & 58 & 16 & 18 & 8 \\
\hline Phase 1 & 27 & 24 & 29 & 20 \\
\hline Phase 2 & 50 & 2 & 22 & 26 \\
\hline
\end{tabular}

The hardness in the T6 condition was used to further assess the effect of solution heat treatment (Fig. 4). Overall, the hardness increased over that of T4 condition. As more Mg, $\mathrm{Zn}$ and $\mathrm{Cu}$ dissolve with longer solution treatment time, the hardness increased after precipitation hardening. A high concentration of $\mathrm{Cu}$ was still present as an intermetallic phase as it could not be taken into solution at $473^{\circ} \mathrm{C}$. Higher hardness could be expected with a high concentration of $\mathrm{Cu}$ in solid solution as it will participate in the precipitation hardening [7]. 


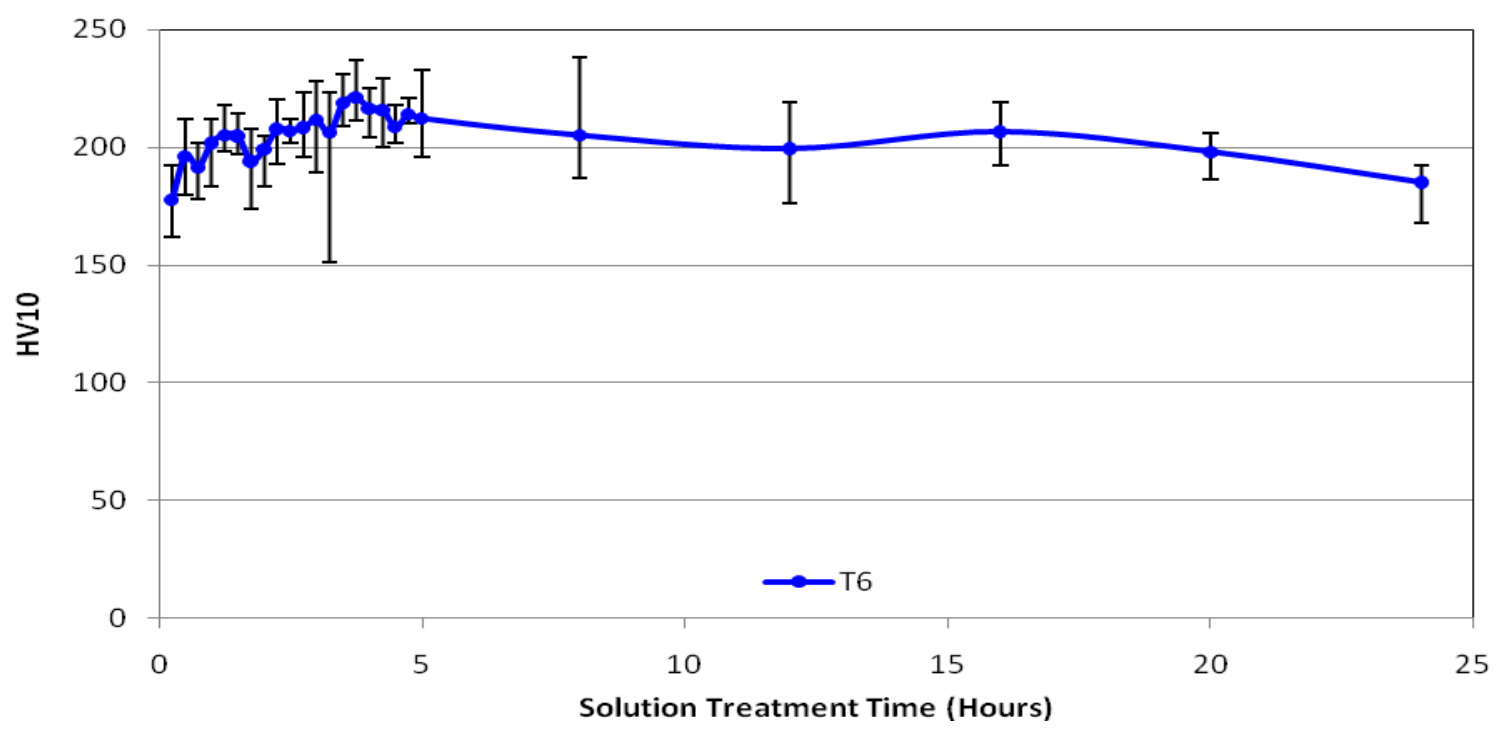

Fig.4: Vickers Hardness Curve for rheocast Al-Zn-Mg-Cu alloy after artificial ageing at $120^{\circ} \mathrm{C}$ for $24 \mathrm{hrs}$.

\section{Conclusions}

The effect of solution heat treatment at $473^{\circ} \mathrm{C}$ on the coarse eutectic phase formed during rheo high pressure die cast (R-HPDC) of the Al-Zn-Mg-Cu alloy was that the eutectic was observed to have dissolved and transformed to $\mathrm{AlMgCuZn}$ and $\mathrm{Al}_{2} \mathrm{CuMg}$ intermetallic phases after solution heat treatment at $473^{\circ} \mathrm{C}$. Both intermetallic phases were still present even after 24 hrs of solution treatment. Solution heat treatment for $24 \mathrm{hrs}$ at $473^{\circ} \mathrm{C}$ was sufficient to dissolve the eutectic for this alloy but higher temperatures are required to completely dissolve the product intermetallic phases.

\section{References}

[1] U.A. Curle: Trans. Nonferrous Met. Soc. China 20(2010), p. 1719

[2] Y. Totik, M. Gavgali: Mater. Character. 49(2003), p. 261

[3] X. Fan, D. Jiang and Q. Meng: Trans. Nonferrous Met. Soc. China 16(2006), p. 577

[4] X. Fan, D. Jiang, Q Meng and L. Zhong: Mater. Letters 60 (2006), p. 1475

[5] K. Chen, H. Liu, Z. Zhang, S Li and R. I. Todd: Journ. Mater. Process. Tech. 142 (2003), p. 190

[6] D.K. Xu, N. Birbilis, D. Lashansky, P.A. Rometsch and B.C. Muddle: Corr. Sci. 53 (2011), p. 217

[7] N.Q. Chinh, J. Lendvai, D. H. Ping and K. Hono: Journ. Alloys and Comp. 378(2004), p. 52 